\title{
Drug Resistance Status
}

National Cancer Institute

\section{Source}

National Cancer Institute. Drug Resistance Status. NCI Thesaurus. Code C102626.

The determination of whether the microbe or lesion is resistant to drugs normally used in treatment. 